\title{
Análises Econômicas de Modelos de Produção com Novilhas de Corte Primíparas aos Dois, Três e Quatro Anos de Idade ${ }^{1}$
}

\author{
Luciana Pötter², José Fernando Piva Lobato ${ }^{3}$, Carlos Guilherme A. Mielitz Netto ${ }^{4}$
}

\begin{abstract}
RESUMO - Este trabalho avaliou, por intermédio de simulações, a economicidade de sistemas de produção de bovinos de corte com novilhas primíparas aos dois (sistema "um ano"), três (sistema "dois anos") e quatro anos (sistema "tradicional") de idade. No sistema "um ano", as fêmeas tiveram três sistemas nutricionais por 100 dias, após a desmama no primeiro outono-inverno, constituída por uma das três alternativas: a) pastejo contínuo em pastagem cultivada de azevém - PAST; b) pastejo contínuo em pastagem natural e suplementação com ração - CNR; c) confinamento com silagem de sorgo + uréia - SIL. Após os 100 dias, as novilhas foram mantidas em conjunto, utilizando-se pastagens naturais melhoradas. Os modelos usados, para comparar os sistemas foram construídos em uma planilha de cálculo Excel, a partir de um modelo original. Os dados biológicos referentes ao sistema "um ano" foram coletados na Empresa Agropecuária Guatambu, Dom Pedrito, RS, em 395 bezerras de corte. A margem bruta anual correspondeu a R \$ 44.066,99, R \$ 41.001,32, $\mathrm{R} \$ 40.509,86, \mathrm{R} \$ 40.045,65$ e R \$ 14.148,08, respectivamente, para os sistemas “dois anos", "um ano” SIL, "um ano" PAST, “um ano" CNR e "tradicional" de produção de bovinos de corte. O custo variável mais elevado foi do sistema "um ano" CNR. Sistemas de produção que fazem uso de tecnologias mais intensivas apresentam resultados superiores ao sistema "tradicional” de produção de bovinos de corte.
\end{abstract}

Palavras-chave: custos variáveis, economicidade em bovinos de corte, idade ao primeiro parto, margem bruta, sistemas de produção

\section{Economic Analyses of a Production Model to Primiparous Beef Heifers at Two, Three and Four Years of Age}

\begin{abstract}
This work, evaluated by means of an economically simulation, the beef production systems with heifers calving by first time at two ("one year" system), three ("two years" system) and four ("traditional" system) years old. In "one year" system, the female calves had three different nutritional systems during 100 days, after weaning in the first autumn/winter, constituted by one of the alternatives: a) continuous grazing on cultivated annual ryegrass - PAST; b) continuous grazing on natural pasture plus diet - CNR; c) feedlot, with sorghum silage plus urea - SIL. After 100 days, the heifers of the three alternatives grazed together on improved natural pastures. The models to compare the systems were constructed on an Excel spreadsheet, based on an original model. The biological data of "one year" system were collected at Guatambu Farm, Dom Pedrito, RS, of 395 beef calves. Annual gross margin was R\$44.066,99, $\mathrm{R} \$ 41.001,32, \mathrm{R} \$ 40.509,86, \mathrm{R}$ \$ 40.045,65 and R\$ 14.148,08, respectively, for “two years”, “one year” SIL, “one year” PAST, “one year" CNR and "traditional" beef productions systems. The variable cost was higher at "one year" CNR. Production systems using more intensifies technologies showed better results than the "traditional" beef cattle system.
\end{abstract}

Key Words: age at first calving, beef cattle economicity, gross margin, production systems, variable costs

\section{Introdução}

De maneira geral, os trabalhos de pesquisa já desenvolvidos com alternativas para o aumento da produtividade pecuária não apresentam e nem discutem a economicidade da aplicação das novas propostas biológicas. Trabalhos e revisões recentes têm propostas efetivas sobre produção, manejo e seleção animal para o aumento da produção e a produtividade animal (LOBATO, 1997), mas não abordam a economicidade de alterações no sistema atual de produção da pecuária de corte.
O objetivo deste trabalho foi determinar, por meio de simulações, a economicidade de três sistemas de produção de bovinos de corte, quando as novilhas são acasaladas pela primeira vez aos 14-15 meses (sistema "um ano"), aos 26-27 meses ( sistema "dois anos") ou aos 36-37 meses (sistema "tradicional") de idade. No sistema "um ano", foram comparados três sistemas alimentares, no pós-desmama, por um período de 100 dias, no outono-inverno. Estes dados são analisados dentro de um sistema de produção de ciclo completo. Para efeito de comparação entre os sistemas foi utilizado o cálculo de margem bruta.

\footnotetext{
1 Parte da Dissertação de Mestrado apresentada à UFRGS pelo primeiro autor.

2 Zootecnista, bolsista do CNPq, Professora PUCRS, Campus II, Uruguaiana, RS. E.mail: potter@pucrs.campus2.br

${ }^{3}$ Prof. Adj. IV, Dep. Zootec., UFRGS. CNPq 1A, CP 776, CEP 90001-970, Porto Alegre-RS. E.mail: lobato@orion.ufrgs.br

${ }^{4}$ Dr., Professor Adjunto III, Departamento de Economia Rural, UFRGS. Porto Alegre. E.mail: mielitz@vortex.ufrgs.br
} 


\section{Material e Métodos}

A partir de um modelo original elaborado por GRAWUNDER (1994), foram construídos novos modelos utilizando uma planilha de cálculo EXCEL, versão 5.0. Os modelos comparam a economicidade de sistemas de produção de bovinos de corte. Os sistemas são diferenciados de acordo com a idade do primeiro serviço das novilhas e os índices tecnológicos que serviram para estruturação dos modelos, estando especificados na Tabela 1. É considerado sistema "tradicional" o primeiro acasalamento das novilhas aos três anos de idade; sistema "dois anos" o primeiro serviço ocorre aos 26-27 meses; e sistema "um ano" aos 14-15 meses de idade.

Para fins metodológicos, fixaram-se datas ou períodos relativos de práticas de manejo com os animais especificados na Tabela 2.

Estruturado o conjunto de equações, foi criada uma situação na qual os coeficientes técnicos assu-

Tabela 1 - Coeficientes técnicos utilizados para estruturação dos modelos que caracterizam o rebanho dos sistemas "um ano", "dois anos" e "tradicional" de produção de bovinos de corte

Table 1 - Technical coefficients used to construct the models of the "one year", "two years" and "traditional" beef herds systems

\begin{tabular}{|c|c|c|c|}
\hline $\begin{array}{l}\text { Coeficientes técnicos } \\
\text { Technical coefficients }\end{array}$ & $\begin{array}{l}\text { Sistema } \\
\text { um ano } \\
\text { One year } \\
\text { system }\end{array}$ & $\begin{array}{l}\text { Sistema } \\
\text { dois anos } \\
\text { Two years } \\
\text { system }\end{array}$ & $\begin{array}{l}\text { Sistema } \\
\text { tradicional } \\
\text { Traditional } \\
\quad \text { system }\end{array}$ \\
\hline Taxa de natalidade (\%) (Reproduction rate [\%]) & 78 & 80 & 50 \\
\hline Relação touro/ventres (\%) (Bull/cows relation [\%]) & 4 & 4 & 4 \\
\hline Descarte de touros $(\%)$ (Bulls culled [\%]) & 25 & 25 & 25 \\
\hline Descarte de bezerras (\%) (Females calves culled [\%]) & 10 & - & - \\
\hline \multicolumn{4}{|l|}{ Taxa de mortalidade (\%) (Mortality rate [\%]) } \\
\hline $\begin{array}{l}\text { - bezerros (calves) } \\
\text { - animais de } 1 \text { a } 2 \text { anos } \\
\text { animals } 1 \text { to } 2 \text { years old }\end{array}$ & $\begin{array}{l}5 \\
2\end{array}$ & $\begin{array}{l}4 \\
3\end{array}$ & $\begin{array}{l}8 \\
4\end{array}$ \\
\hline $\begin{array}{l}\text { - animais de } 2 \text { a } 3 \text { anos } \\
\text { animals } 2 \text { to } 3 \text { years old }\end{array}$ & - & 1 & 3 \\
\hline $\begin{array}{l}\text { - animais de } 3 \text { a } 4 \text { anos } \\
\text { animals } 3 \text { to } 4 \text { years old }\end{array}$ & - & - & 2 \\
\hline - vacas (cows) & 1 & 0,5 & 5 \\
\hline \multicolumn{4}{|l|}{ Peso de venda $(\mathrm{kg})$ (Sale liveweight) } \\
\hline $\begin{array}{l}\text { - machos de } 4,5 \text { anos } \\
\text { males } 4.5 \text { years old }\end{array}$ & - & - & 460 \\
\hline $\begin{array}{l}\text { - machos de } 2 \text { anos } \\
\text { males } 2 \text { years old }\end{array}$ & 420 & 440 & - \\
\hline $\begin{array}{l}\text { - vacas de descarte } \\
\text { cowsculled }\end{array}$ & 440 & 450 & 365 \\
\hline $\begin{array}{l}\text { - bezerras de descarte (females calves culled) } \\
\text { - touros (bulls) }\end{array}$ & $\begin{array}{l}130 \\
600\end{array}$ & $600^{-}$ & $600^{-}$ \\
\hline \multicolumn{4}{|l|}{ Campo nativo (UA/ha) (Natural pasture [AU/ha]) } \\
\hline $\begin{array}{l}-01 / 04 \text { a } 30 / 08(04 / 01 \text { to } 08 / 30) \\
\text { - } 01 / 09 \text { a } 30 / 09(09 / 01 \text { to } 09 / 30) \\
\text { - } 01 / 10 \text { a } 30 / 11(10 / 01 \text { to } 11 / 30) \\
\text { - } 01 / 12 \text { a } 31 / 03(12 / 01 \text { to } 03 / 31)\end{array}$ & $\begin{array}{l}0,66 \\
0,80 \\
0,80 \\
1,00\end{array}$ & $\begin{array}{l}0,66 \\
0,80 \\
0,80 \\
1,00\end{array}$ & $\begin{array}{l}0,66 \\
0,66 \\
0,93 \\
0,93\end{array}$ \\
\hline
\end{tabular}

Pastagem melhorada hibernal

Winter improved pasture

- bezerras (females calves)

- bezerros (males calves)

- machos sobreano (males yearlings)

1,0

0,8

- fêmeas sobreano (females yearlings)

1,0

$\begin{array}{ll}1,3 & - \\ 2,0 & - \\ 0,8 & - \\ 2,0 & -\end{array}$

Adaptado de GRAWUNDER, 1988; MIELITZNETTO, 1979; PÖTTERE SILVA, 1986; ROCHA, 1997; PÖTTER, 1996.

Adapted from GRAWUNDER, 1988; MIELITZ NETTO, 1979; PÖTTER E SILVA, 1986; ROCHA, 1997; PÖTTER, 1996.

* Unidade Animal (U.A.) $=450 \mathrm{~kg}$ de peso vivo.

* Animal unit (A.U.) $=450 \mathrm{~kg}$ of liveweight. 
miram os parâmetros próprios dos sistemas de criação "um ano", "dois anos" e "tradicional" de produção de bovinos de corte no Estado do Rio Grande do Sul. A partir destes parâmetros, foram determinados custos variáveis, receita bruta, margem bruta e margem bruta mais agricultura para cada sistema. Os modelos foram dimensionados para uma área de 1000 ha.

No sistema "um ano", o modelo prevê para bezerras a utilização de alimentação hibernal diferenciada, no pós-desmama, por 100 dias (final do outono ao final do inverno). Esta alimentação foi constituída por uma das seguintes alternativas: a) pastejo contínuo, em pastagem de azevém (Lolium multiflorum Lam.), implantada sobre uma resteva de soja-PAST; b) pastejo contínuo em pastagem natural e suplementação com ração-CNR (16\% de proteína bruta; $70 \%$ de nutrientes digestíveis totais (NDT), na quantidade diária de 1,5\% em matéria seca (MS) do peso corporal dos animais, ajustada mensalmente; e c) confinamento, recebendo à vontade, silagem de sorgo + uréia-SIL (ROCHA, 1997). Após a aplicação dos três sistemas alimentares, as bezerras do sistema "um ano" permaneceram como um só rebanho, em pastagem melhorada com azevém, trevo branco (Trifolium repens) e cornichão (Lotus corniculatus cv. São Gabriel) até o final do primeiro acasalamento (24/01/1995).
Os preços utilizados para o cálculo de custos e receitas foram extraídos de PÖTTER (1996) e correspondem aos preços pagos e recebidos pela Empresa Agropecuária Guatambu, ano pecuário 95/96.

Os itens que entraram na composição dos custos variáveis para os sistemas "um ano", "dois anos" e "tradicional" foram: carrapaticidas, vermífugos, vacinas, sal, renovação de reprodutores, FUNRURAL, mão-de-obra, pastagem cultivada de inverno, adubação de manutenção das pastagens e roçadas. Os itens referentes aos custos do sistema "um ano", diferenciados pela suplementação recebida no período hibernal, foram pastagem cultivada de inverno, ração, cochos, silagem, distribuição da alimentação, uréia, sulfato de amônia e roçadas. Tratores e outros implementos agrícolas foram utilizados para atividades como adubação de pastagens, roçadas, confecção de silagem e distribuição de suplementos.

As receitas foram computadas da seguinte forma:

- Venda de vacas: preço pago pelo kg vivo da vaca magra em 31/03 x peso vivo médio dos animais vendidos no sistema "tradicional" e preço pago pelo kg vivo da vaca gorda na data da venda $\mathrm{x}$ peso vivo médio das vacas vendidas nos sistemas "dois anos" e "um ano";

- Venda de machos de 4,5 anos: preço pago pelo $\mathrm{kg}$ vivo do novilho em $31 / 03 \mathrm{x}$ peso vivo médio dos

Tabela 2 - Datas ou períodos relativos de práticas de manejo realizadas com os animais nos sistemas "um ano", "dois anos" e "tradicional" de produção de bovinos de corte

Table 2 - Dates or periods of management practices conducted with animals at "one year", "two years" and "traditional" systems of beef cattle production

\begin{tabular}{|c|c|c|c|}
\hline $\begin{array}{l}\text { Práticas de manejo } \\
\text { Management practices }\end{array}$ & $\begin{array}{l}\text { Sistema } \\
\text { um ano } \\
\text { One year } \\
\text { system }\end{array}$ & $\begin{array}{l}\text { Sistema } \\
\text { dois anos } \\
\text { Two years } \\
\text { system }\end{array}$ & $\begin{array}{l}\text { Sistema } \\
\text { tradicional } \\
\text { Traditional } \\
\text { system }\end{array}$ \\
\hline Parição (data média) & $01 / 10$ & $01 / 10$ & $01 / 10$ \\
\hline Calving (mean date) & $10 / 01$ & $10 / 01$ & $10 / 01$ \\
\hline Desmama & $31 / 03$ & $31 / 03$ & $15 / 10$ \\
\hline Weaning & $02 / 31$ & $03 / 31$ & $03 / 31$ \\
\hline Período de acasalamento & $10 / 11$ a $25 / 01$ & $10 / 11$ a $25 / 01$ & $15 / 11$ a $15 / 02$ \\
\hline Mating period & $11 / 10$ to $01 / 25$ & $11 / 10$ to $01 / 25$ & $11 / 15$ to $02 / 15$ \\
\hline Venda de novilhos & $30 / 06,31 / 07,31 / 08,30 / 09$ e $30 / 10$ & $30 / 09$ e $31 / 10$ & $31 / 03$ \\
\hline Steers sale & $06 / 30,07 / 31,08 / 31,09 / 30$ and $10 / 30$ & $09 / 30$ to $10 / 31$ & $03 / 31$ \\
\hline Venda de vacas & $30 / 04$ & $30 / 04$ & $31 / 03$ \\
\hline Cows sale & $04 / 30$ & $04 / 30$ & $03 / 31$ \\
\hline Venda de touros descarte & $31 / 10$ & $31 / 10$ & $31 / 03$ \\
\hline Culled bulls sale & $10 / 31$ & $10 / 31$ & $03 / 31$ \\
\hline Venda de bezerras & $30 / 04$ & - & - \\
\hline Female calves sale & $40 / 30$ & - & - \\
\hline
\end{tabular}

Adaptado de GRAWUNDER, 1988; MIELITZ NETTO, 1979; PÖTTER E SILVA, 1986; ROCHA, 1997; PÖTTER, 1996.

Adapted from GRAWUNDER, 1988; MIELITZ NETTO, 1979; PÖTTER E SILVA, 1986; ROCHA, 1997; PÖTTER, 1996. 
animais vendidos;

- Venda de touros de descarte: preço pago pelo $\mathrm{kg}$ vivo do touro na venda x peso médio dos animais vendidos;

- Venda de machos de dois anos: preço pago pelo $\mathrm{kg}$ vivo do novilho gordo $\mathrm{x}$ peso vivo médio;

- Venda de bezerras de descarte: preço médio pago nos remates da região; e

- Venda de soja, correspondente ao arrendamento para os sistemas "dois anos" e "um ano": preço médio anual x número de sacos de soja recebidos, considerando um arrendamento de três sacos de soja/ha.

Nos modelos estão previstos rebanhos estabilizados. Para efeito de comparações, foi considerado o cálculo de margem bruta e margem bruta + agricultura, considerando o faturamento com a venda da soja, que era terceirizada.

\section{Resultados e Discussão}

Na Tabela 3, está apresentado o desfrute em número de animais comercializados e em $\mathrm{kg}$ de peso vivo produzidos por categoria animal para os sistemas estudados.

No sistema "um ano" (PAST, CNR e SIL), os novilhos representam 50,78\%; as vacas de descarte,
$46,20 \%$; as bezerras de descarte, $1,64 \%$; e os touros, $1,38 \%$ do total da produção de peso vivo. A contribuição das vacas de descarte foi inferior, devido ao descarte anterior das bezerras. As bezerras comercializadas com baixo peso (130 kg) não produzem impacto positivo no sistema. Com o crescimento do mercado de carne de melhor qualidade nos grandes centros consumidores, surgem como alternativas o engorde e a comercialização destas novilhas para o abate, com maior remuneração.

No sistema "dois anos", o percentual da produção de peso vivo é equilibrado entre vacas de descarte e novilhos, 50,32 e 49,40\%, respectivamente. Este equilíbrio é explicado pelo número de animais comercializados, 111,88 vacas de descarte e 114,61 novilhos, e pelo peso dos animais comercializados, $440 \mathrm{~kg}$ para os novilhos e $450 \mathrm{~kg}$ para as vacas de descarte. Os 1,28\% restantes correspondem à categoria de touros de descarte.

Observou-se que a maior contribuição na produção de peso vivo para o sistema "tradicional" corresponde aos novilhos $(58,63 \%)$, semelhante aos $59,96 \%$ observados por MIELITZ NETTO (1979), e à venda do pequeno número $(62,18)$ de vacas de invernar, além do seu baixo peso $(365 \mathrm{~kg})$. A permanência das vacas de descarte no rebanho até atingi-

Tabela 3 - Desfrute em número de animais comercializados e quilogramas de peso vivo produzidos por categoria animal pelos sistemas "um ano" (PAST, CNR e SIL), "dois anos" e "tradicional" de produção de bovinos de corte

Table 3 - $\quad$ Outcome rate in number of animals sold and kilograms of live weight produced per animal categorie of the "One year" (PAST, CNR and SIL), "two years" and "traditional" production systems of beef cattle

\begin{tabular}{|c|c|c|c|c|}
\hline $\begin{array}{l}\text { Categoria } \\
\text { animal } \\
\text { Animal category }\end{array}$ & $\begin{array}{c}\text { Sistema um ano } \\
\text { "PAST" } \\
\text { One year system } \\
\text { "PAST" }\end{array}$ & $\begin{array}{l}\text { Sistema um ano } \\
\text { "CNR e SIL" } \\
\text { One year system } \\
\text { "CNR e SIL" }\end{array}$ & $\begin{array}{l}\text { Sistema dois } \\
\text { anos } \\
\text { Two years } \\
\text { system }\end{array}$ & $\begin{array}{c}\text { Sistema } \\
\text { tradicional } \\
\text { Traditional } \\
\text { system }\end{array}$ \\
\hline $\begin{array}{l}\text { Novilhos } \\
\text { Steers }\end{array}$ & 135,02 & 128,07 & 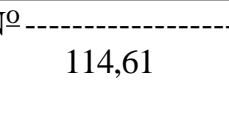 & 77,09 \\
\hline $\begin{array}{l}\text { Vacas } \\
\text { Cows }\end{array}$ & 117,25 & 111,22 & 111,88 & 62,18 \\
\hline $\begin{array}{l}\text { Touros } \\
\text { Bulls }\end{array}$ & 2,56 & 2,43 & 2,19 & 3,82 \\
\hline $\begin{array}{l}\text { Bezerras } \\
\text { Female calves }\end{array}$ & 14,09 & 13,37 & & \\
\hline Total & 268,93 & 255,09 & 228,68 & 143,10 \\
\hline $\begin{array}{l}\text { Novilhos } \\
\text { Steers }\end{array}$ & $56.708,09$ & $53.790,92$ & $50.428,77$ & $35.460,62$ \\
\hline $\begin{array}{l}\text { Vacas } \\
\text { Cows }\end{array}$ & 51591,85 & $48.937,87$ & $50.346,33$ & $22.697,07$ \\
\hline $\begin{array}{l}\text { Touros } \\
\text { Bulls }\end{array}$ & 1537,40 & 1458,31 & 1312,43 & 2294,33 \\
\hline $\begin{array}{l}\text { Bezerras } \\
\text { Female calves }\end{array}$ & 1831,81 & 1737,58 & & \\
\hline Total & $111.669,14$ & $105.924,67$ & $102.087,53$ & $60.452,02$ \\
\hline
\end{tabular}


Rev. bras. zootec.

rem o peso de venda gordas implicaria em redução do número de fêmeas, pois coincide com os meses de outono de menor disponibilidade forrageira (FREITAS et al., 1976). O pequeno número de fêmeas a ser descartado é conseqüência da baixa taxa de natalidade do sistema "tradicional".

$\mathrm{Na}$ Tabela 4, estão quantificados os itens que contribuem para a composição dos custos dos sistemas analisados.
A maior quantidade de carrapaticida utilizada no sistema "tradicional", 93,37 litros, quando comparado com os sistemas "dois anos" e "um ano" (PAST, CNR e SIL), que utilizaram, respectivamente, 9,32; 5,04; 5,31; e 5,31 litros de carrapaticida, mostra que, em sistemas mais intensivos, há redução do número de banhos e das categorias a receber o tratamento. Este elevado uso de carrapaticida para o sistema "tradicional", em parte, é justificado pelo princípio

Tabela 4 - Composição dos custos variáveis para os sistemas "um ano" (PAST, CNR e SIL), "dois anos" e "tradicional" de produção de bovinos de corte em uma propriedade com 1000 ha. Dados em R\$

Table 4 - Composition of the variable costs "one year"(PAST, CNR and SIL), "two years" and "traditional" of beef production systems in a property of 1000 ha. Data in $R \$$

\begin{tabular}{|c|c|c|c|c|c|}
\hline & & & $\begin{array}{l}\text { Sistemas } \\
\text { Systems }\end{array}$ & & \\
\hline $\begin{array}{l}\text { Custo variável } \\
\text { Variable cost }\end{array}$ & $\begin{array}{l}\text { "Um ano" } \\
\text { PAST } \\
\text { "One year" } \\
\text { PAST }\end{array}$ & $\begin{array}{l}\text { "Um ano" } \\
\text { CNR } \\
\text { "One year" } \\
\text { CNR }\end{array}$ & $\begin{array}{l}\text { "Um ano" } \\
\text { SIL } \\
\text { "One year" } \\
\text { SIL }\end{array}$ & $\begin{array}{c}\text { "Dois } \\
\text { anos" } \\
\text { "Two years" }\end{array}$ & $\begin{array}{c}\text { Tradicional } \\
\text { Traditional }\end{array}$ \\
\hline $\begin{array}{l}\text { Carrapaticida (1) } \\
\text { Tick medicament }(l)\end{array}$ & 5,04 & 5,31 & 5,31 & 9,32 & 93,37 \\
\hline $\begin{array}{l}\text { Vermífugo (l) } \\
\text { Vermifuge }(l)\end{array}$ & 27,15 & 28,61 & 28,61 & 33,07 & 5,19 \\
\hline $\begin{array}{l}\text { Vacinas (doses) } \\
\text { Vacines }(\text { doses })\end{array}$ & 4213,81 & 4442,33 & 4442,33 & 4165,74 & 3384,19 \\
\hline $\begin{array}{l}\text { Sal mineral }(\mathrm{kg}) \\
\text { Mineral salt }(\mathrm{kg})\end{array}$ & 7932,04 & 8362,20 & 8362,20 & 8630,18 & 11346,84 \\
\hline $\begin{array}{l}\text { Touros }\left(\mathrm{n}^{\underline{\mathrm{o}}}\right) \\
\text { Bulls }\left(n^{\underline{o}}\right)\end{array}$ & 2,43 & 2,56 & 2,56 & 2,19 & 3,82 \\
\hline $\begin{array}{l}\text { FUNRURAL }(\%) \\
\operatorname{Tax}(\%)\end{array}$ & 2,20 & 2,20 & 2,20 & 2,20 & 2,20 \\
\hline $\begin{array}{l}\text { Mão-de-obra (no.) } \\
\text { Labor } \\
\text { Pastagem melhorada (ha) }\end{array}$ & 4,0 & 4,0 & 4,0 & 3,0 & 4,84 \\
\hline $\begin{array}{l}\text { Improved pasture } \\
\text { Implantação }\end{array}$ & 72,62 & 76,56 & 76,56 & 69,16 & - \\
\hline $\begin{array}{l}\text { Plowing and sowing } \\
\text { Manutenção } \\
\text { Year keeping }\end{array}$ & 217,87 & 229,69 & 229,69 & 207,48 & - \\
\hline $\begin{array}{l}\text { Roçada (ha) (Mower) } \\
\text { Alimentação um ano } \\
\text { One yearfeeding }\end{array}$ & 145,25 & 153,13 & 153,13 & 138,32 & - \\
\hline $\begin{array}{l}\text { Pastagem anual (ha) } \\
\text { Annual pasture }\end{array}$ & 50,16 & - & - & - & - \\
\hline $\begin{array}{l}\text { Ração }(\mathrm{t}) \\
\text { Diet }\end{array}$ & - & 34,31 & - & - & - \\
\hline $\begin{array}{l}\text { Cochos }(\mathrm{m}) \\
\text { Troughs }\end{array}$ & - & 31,31 & 41,33 & - & - \\
\hline $\begin{array}{l}\text { Silagem }(\mathrm{t}) \\
\text { Silage }\end{array}$ & - & - & 250,46 & - & - \\
\hline $\begin{array}{l}\text { Distrib.alimentação }(\mathrm{h}) \\
\text { Feeding distribuition }\end{array}$ & - & 50,00 & 200,00 & - & - \\
\hline $\begin{array}{l}\text { Uréia + sulfato }(\mathrm{kg}) \\
\text { Urea + sulfate }\end{array}$ & - & - & 1251,83 & - & - \\
\hline Roçada (ha) (Mower) & - & 80,11 & - & - & - \\
\hline
\end{tabular}

$\mathrm{R} \$ 1,00=\mathrm{U} \$ 0,87$. 
ativo utilizado, que necessita de uma concentração de produto quatro vezes superior. Para um sistema semelhante, MIELITZ NETTO (1979) obteve consumo de 63,79 litros de carrapaticida com o mesmo princípio ativo, devido à maior infestação de carrapatos nos campos naturais.

Quanto à demanda de vermífugos (Tabela 4), a ordem é inversa, pois o sistema "tradicional" faz pouco uso destes, 5,19 litros, quando comparado com os sistemas "dois anos" e "um ano" (PAST, CNR e SIL), que utilizaram, respectivamente, 33,07; 27,15; 28,61; e 28,61 litros de vermífugo.

A quantidade necessária de vacinas, sal mineral e reprodutores para renovação é proporcional ao número de animais existentes em cada sistema, com a ressalva de que os sistemas "dois anos" e "um ano" prevêem a utilização de vacinas para leptospirose e tristeza parasitária bovina, o que não ocorre no "sistema tradicional".

Os itens que contribuem para a composição do custo da suplementação hibernal das fêmeas no sistema "um ano" estão na Tabela 4. A quantidade da alimentação fornecida (pastagem, ração + campo nativo ou silagem + uréia), da área a ser roçada e da quantidade de cochos é diretamente dependente do número de bezerras a ser suplementadas. Quanto à distribuição da suplementação, além da dependência do número de animais, a proximidade do depósito no caso da ração ou, a proximidade do silo no caso da silagem, também passa a influir nas horas gastas com implementos para distribuição da mesma. O maior tempo gasto com implementos no sistema SIL é explicado pelo maior volume da silagem em relação à ração.

A receita bruta obtida com o sistema "tradicional” foi de R $\$ 38.256,78$ (Tabela 5), ou seja, 48,21; 50,33; 52,88; e 52,88\% inferior aos sistemas "dois anos" e "um ano" (PAST, CNR e SIL), respectivamente. Este menor resultado do sistema "tradicional" é reflexo do baixo número de animais desfrutados pelo sistema e também da baixa produção de peso vivo, conseqüência da baixa taxa de natalidade (50\%), concordando com as posições de LOBATO (1985; 1997) e com os resultados obtidos por MIELITZ NETTO (1979), o qual afirma que qualquer mudança tecnológica na pecuária de corte deve passar por aumento na taxa de natalidade.

Nos sistemas "dois anos" e "um ano" (PAST, CNR e SIL), a receita bruta foi de $\mathrm{R} \$ 73.859,71$, $\mathrm{R} \$ 77.019,91, \mathrm{R} \$ 81.196,83$ e $\mathrm{R} \$ 81.196,83$, respectivamente (Tabela 5). A pequena diferença entre as receitas dos sistemas "dois anos" e "um ano" é explicada pela limitação de área no outono, devido à utilização de pastagens melhoradas no inverno, as quais têm o seu ponto de estrangulamento entre abril e junho, quando a capacidade de suporte destas pastagens é mais baixa. Este déficit forrageiro é explicado por JACQUES (1993), ao afirmar que as forrageiras ditas de inverno não produzem com temperaturas inferiores a $10^{\circ} \mathrm{C}$, e mesmo com implantação no início do outono, a utilização anterior a julho resulta em rebrote muito lento, apresentando condições para consumo somente em agosto-setembro. Nos meses de abril a junho, a contribuição das pastagens hibernais perenes é mínima, correspondendo ao período de estabelecimento e crescimento das mesmas.

No sistema SIL, no período de primavera-verão, parte da área é ocupada com a lavoura de sorgo. O reflexo desta utilização de área sobre a composição do rebanho é nulo, pois o ponto de estrangulamento para o aumento no número de vacas está localizado na maior ou menor disponibilidade de área durante o outono. Além disso, a alta produtividade da lavoura de sorgo exige apenas $6,56 \mathrm{ha}$, ou seja, $0,7 \%$ da área total para a produção de silagem. A baixa contribuição da categoria de bezerras de descarte na receita bruta do sistema "um ano"(PAST, CNR e SIL), R \$1.059,92, $\mathrm{R} \$ 1.117,40$ e $\mathrm{R} \$ 1.117,40$, respectivamente, também responde por esta pequena diferença.

Independente do sistema, a maior contribuição na receita bruta provém da categoria de novilhos, independentemente da idade e do preço comercializado (Tabela 5). Os sistemas "um ano" (PAST, CNR e SIL), "dois anos" e "tradicional" apresentam na composição da receita bruta, respectivamente, 59,36; 58,03; e 66,74\% provenientes da venda de novilhos. PÖTTER e SILVA (1986) obtiveram, para os sistemas "convencional" e "melhorado", que corresponderiam aos sistemas "tradicional" e "dois anos", contribuição na receita de 62,06 e 60,03\%, respectivamente, bastante similares aos obtidos neste trabalho. A menor contribuição das vacas de descarte no sistema "tradicional" $(29,66 \%)$, quando comparada com os sistemas "dois anos" $(40,90 \%)$ e "um ano" (38,12\%), é o resultado da venda de vacas de invernar com $365 \mathrm{~kg}$ ao preço de $\mathrm{R} \$ 0,50 / \mathrm{kg}$. Os outros sistemas comercializam vacas de descarte por $\mathrm{R} \$ 0,60 / \mathrm{kg}$, em abril, com peso de $440 \mathrm{~kg}$ para o sistema "um ano" e $450 \mathrm{~kg}$ para o sistema "dois anos".

Os insumos utilizados pelos diferentes sistemas, que constituem o custo variável, estão contabilizados na Tabela 6. 
Rev. bras. zootec.

Tabela 5 - Receita bruta por categoria animal nos sistemas "um ano" (PAST, CNR e SIL), "dois anos" e "tradicional" de produção de bovinos de corte em uma propriedade com 1000 ha durante um ano (dados em $\mathrm{R} \$$ e \%)

Table 5 - Gross income per animal category at "one year" (PAST, CNR and SIL), "two years" and "traditional" beef production systems in a 1000 ha property during one year (data in $R \$$ and \%)

\begin{tabular}{|c|c|c|c|c|}
\hline $\begin{array}{l}\text { Categoria } \\
\text { animal } \\
\text { Animal } \\
\text { categorie }\end{array}$ & $\begin{array}{l}\text { Sistema "um ano" } \\
\text { "PAST" } \\
\text { "One year" system } \\
\text { "PAST" }\end{array}$ & $\begin{array}{l}\text { Sistema "um ano" } \\
\text { "CNR e SIL" } \\
\text { "One year" system } \\
\text { "CNR e SIL" }\end{array}$ & $\begin{array}{c}\text { Sistema "dois } \\
\text { anos" } \\
\text { "Two years" } \\
\text { system } \\
\end{array}$ & $\begin{array}{c}\text { Sistema } \\
\text { tradiciona } \\
\text { Traditional } \\
\text { system } \\
\end{array}$ \\
\hline $\begin{array}{l}\text { Novilhos } \\
\text { Steers }\end{array}$ & $45.722,28$ & $48.201,87$ & $42.864,46$ & $25.531,65$ \\
\hline $\begin{array}{l}\text { Vacas } \\
\text { Cows }\end{array}$ & $29.362,72$ & $30.955,11$ & $30.270,80$ & $11.348,54$ \\
\hline $\begin{array}{l}\text { Touros } \\
\text { Bulls } \\
\text { Bezerras } \\
\text { Females calves }\end{array}$ & $\begin{array}{r}874,99 \\
1059,92\end{array}$ & $\begin{array}{r}922,44 \\
1117,40\end{array}$ & 787,46 & 1376,60 \\
\hline Total & $77.019,91$ & $81.196,63$ & $73.859,71$ & $38.256,78$ \\
\hline $\begin{array}{l}\text { Novilhos } \\
\text { Steers }\end{array}$ & 59,36 & 59,36 & 58,03 & 66,74 \\
\hline $\begin{array}{l}\text { Vacas } \\
\text { Cows }\end{array}$ & 38,12 & 38,12 & 40,90 & 29,66 \\
\hline $\begin{array}{l}\text { Touros } \\
\text { Bulls }\end{array}$ & 1,14 & 1,14 & 1,07 & 3,60 \\
\hline $\begin{array}{l}\text { Bezerras } \\
\text { Females calves }\end{array}$ & 1,38 & 1,38 & & \\
\hline Total & 100,00 & 100,00 & 100,00 & 100,00 \\
\hline
\end{tabular}

$\mathrm{R} \$ 1,00=\mathrm{U} \$ 0,87$.

Na Tabela 6, é observado que, independente do sistema analisado, o custo mais elevado é a mão-deobra, $\mathrm{R} \$ 10.360,47, \mathrm{R} \$ 7.922,69$ e $\mathrm{R} \$ 12.408,37$, para os sistemas "um ano" (PAST, CNR e SIL), "dois anos" e "tradicional", respectivamente. A mão-deobra no sistema PAST representa $28,38 \%$; sistema CNR, 25,17\%; SIL, 25,77\%; "dois anos", 26,59\%; e "tradicional”, 51,47\%. GRAWUNDER (1992), ao analisar um sistema tradicional, também apontou como maior custo variável a mão-de-obra, contribuindo com $42,15 \%$. A empresa SAFRAS e CIFRAS (1996), considerando a média de seus produtores assistidos nos anos agrícolas de 94/95 e 95/96, com melhores índices de produtividade, obteve, respectivamente, participação de 27,64 e 24,45\% correspondentes ao item mão-de-obra, semelhantes aos obtidos neste trabalho.

Os produtos veterinários (carrapaticidas, vacinas e vermífugos) e o sal mineral contabilizaram para os sistemas PAST, CNR e SIL, "dois anos" e "tradicional”, respectivamente, $\mathrm{R} \$ 7.074,94, \mathrm{R} \$ 7.458,62$, $\mathrm{R} \$ 7.458,62, \mathrm{R} \$ 7.137,56$ e R $\$ 6.078,84$ (Tabela 6). A contribuição percentual dos produtos veterinários e do sal mineral para os sistemas PAST, CNR, SIL e "dois anos", correspondeu, respectivamente, a 19,37; 18,13 ; 18,55 ; e $23,97 \%$. O sistema "tradicional" totalizou $25,20 \%$, semelhante aos $29,23 \%$ obtidos por GRAWUNDER (1992).

A implantação e manutenção das pastagens totalizaram R $\$ 9589,89$ para o sistema “um ano" PAST, R\$10.109,96 para os sistemas "um ano" CNR e SIL e R\$9.132,53 para o sistema “dois anos". Quando se consideram a implantação e a manutenção das pastagens como um só custo, este ultrapassa os percentuais referentes à mão-de-obra, 26,27\% para o sistema "um ano" PAST, 24,56\% para o sistema CNR, 25,15\% para SIL e $30,65 \%$ para o sistema "dois anos" (Tabela 6). GRAWUNDER (1992), em dois sistemas distintos de idade de desmama, o tradicional, aos sete meses, com abate aos dois anos de idade, e o desmame precoce, aos 90 dias, e abate, também aos dois anos de idade, obteve contribuição no custo variável de 43,25 e $50,11 \%$, respectivamente. A roçada representou um custo bastante baixo, 3,57\% para o sistema "um ano" PAST, 3,34\% para CNR, 3,42\% para SIL e 4,16\% para o sistema "dois anos" (Tabela 6).

Nos sistemas que realizam o primeiro acasalamento das novilhas aos 14 meses de idade, o 
custo da suplementação hibernal representou 9,45\% para o sistema PAST, $16,67 \%$ para CNR e $14,69 \%$ para SIL. O sistema "um ano", que apresentou maior custo com alimentação hibernal, foi o CNR ( $\mathrm{R} \$ 6.859,27)$. No entanto, o sistema apresenta como grande vantagem um risco quase nulo no fornecimento da ração, pois não é afetado por condições climáticas. De acordo com PÖTTER (1995), é importante a garantia de estabilidade do preço da ração no período de suplementação.

O resultado econômico dos cinco sistemas de produção de bovinos de corte, o qual compreende receita bruta, custos variáveis, margem bruta (receita bruta - custos variáveis) e margem bruta incluindo a receita obtida com o arrendamento proveniente da agricultura, consta da Tabela 7. Não foram contabilizados, na presente análise, os gastos refe- rentes aos custos fixos (depreciação e manutenção).

O sistema que proporcionou a maior margem bruta foi o "dois anos", considerando-se ou não a receita proveniente do arrendamento para agricultura (R \$44.066,99e R \$46.556,78). Este, quando comparado com os resultados obtidos para os sistemas "um ano", foi 3,62; 6,40; e 8,77\% superior aos sistemas "um ano" PAST, CNR e SIL, respectivamente. O sistema "tradicional”, com margem bruta de apenas $\mathrm{R} \$ 14.148,08$, foi superado pelo sistema "dois anos" em 229,07\%.

A baixa margem bruta obtida no sistema "tradicional" é resultado da baixa receita bruta proporcionada pelo sistema, já comentado anteriormente. A venda dos animais concentra-se no mês de março, período de safra, com preços inferiores, achatando ainda mais a receita bruta.

A superioridade econômica do sistema "dois anos"

Tabela 6 - Custos variáveis dos sistemas "um ano" (PAST, CNR e SIL), "dois anos" e "tradicional" de produção de bovinos de corte em uma propriedade com 1000 ha (dados em $R \$$ )

Table 6 - Variable costs of "one year" (PAST, CNR and SIL), "two years" and "traditional" of beef cattle production systems in a 1000 ha property (data in $R \$$ )

\begin{tabular}{|c|c|c|c|c|c|}
\hline \multirow[b]{2}{*}{$\begin{array}{l}\text { Custo variável } \\
\text { Variable cost }\end{array}$} & \multicolumn{5}{|c|}{$\begin{array}{l}\text { Sistemas } \\
\text { Systems }\end{array}$} \\
\hline & PAST & $\begin{array}{l}\text { Um Ano } \\
\text { CNR } \\
\text { "One year" } \\
\text { CNR }\end{array}$ & SIL & $\begin{array}{c}\text { Dois } \\
\text { anos } \\
\text { "Two year" }\end{array}$ & $\begin{array}{r}\text { Tradicional } \\
\text { Traditional }\end{array}$ \\
\hline $\begin{array}{l}\text { Carrapaticida } \\
\text { Tick medicament }\end{array}$ & 136,01 & 143,39 & 143,39 & 251,61 & 933,75 \\
\hline $\begin{array}{l}\text { Vermífugo } \\
\text { Vermifuge }\end{array}$ & 2792,64 & 2944,08 & 2944,08 & 2653,01 & 301,23 \\
\hline $\begin{array}{l}\text { Vacinas } \\
\text { Vacines }\end{array}$ & 2087,93 & 2201,16 & 2201,16 & 1993,41 & 1139,12 \\
\hline $\begin{array}{l}\text { Sal mineral } \\
\text { Mineral salt }\end{array}$ & 2058,36 & 2169,99 & 2169,99 & 2239,53 & 3704,74 \\
\hline $\begin{array}{l}\text { Touros } \\
\text { Bulls }\end{array}$ & 3038,15 & 3202,92 & 3202,92 & 2734,22 & 4779,85 \\
\hline $\begin{array}{l}\text { FUNRURAL } \\
\text { Tax }\end{array}$ & 1694,44 & 1786,33 & 1786,33 & 1624,91 & 841,65 \\
\hline $\begin{array}{l}\text { Mão-de-obra } \\
\text { Labor }\end{array}$ & $10.360,47$ & $10.360,47$ & $10.360,47$ & 7922,69 & $12.408,37$ \\
\hline $\begin{array}{l}\text { Pastagem melhorada } \\
\text { Improved pasture }\end{array}$ & & & & & \\
\hline $\begin{array}{l}\text { Implantação } \\
\text { Plowing and sowing }\end{array}$ & 4131,12 & 4355,16 & 4355,16 & 3934,10 & - \\
\hline $\begin{array}{l}\text { Manutenção } \\
\text { Year keeping }\end{array}$ & 5458,77 & 5754,80 & 5754,80 & 5198,43 & - \\
\hline $\begin{array}{l}\text { Roçada } \\
\text { Mower }\end{array}$ & 1302,94 & 1373,61 & 1373,61 & 1240,81 & - \\
\hline $\begin{array}{l}\text { Alimentação um ano } \\
\text { One year feeding }\end{array}$ & 3449,22 & 6859,27 & 5903,60 & - & \\
\hline Total & $36.510,05$ & $41,151,17$ & $40,195,50$ & $29,792,72$ & $24,108,70$ \\
\hline
\end{tabular}


Rev. bras. zootec.

Tabela 7 - Receita bruta, custos variáveis, margem bruta e margem bruta + agricultura obtidas para os sistemas "um ano" (PAST, CNR e SIL), "dois anos" e "tradicional" de produção de bovinos de corte em uma propriedade com 1000 ha (dados em $\mathrm{R} \$$ )

Table 7 - Gross income, variables custs, gross margin and gross margin + agriculture obtained at "one year" (PAST, CNR and SIL), "two years" and "traditional" beff production systems in a 1000 ha property (data in $R \$$ )

\begin{tabular}{lcccc}
\hline $\begin{array}{l}\text { Sistemas } \\
\text { Systems }\end{array}$ & $\begin{array}{c}\text { Receita bruta } \\
\text { Gross income }\end{array}$ & $\begin{array}{c}\text { Custos variáveis } \\
\text { Variable costs }\end{array}$ & $\begin{array}{c}\text { Margem bruta } \\
\text { Gross margin }\end{array}$ & $\begin{array}{c}\text { Margem bruta + } \\
\text { agricultura } \\
\text { Gross margin }+ \\
\text { Agriculture }\end{array}$ \\
\hline $\begin{array}{l}\text { Um ano PAST } \\
\text { One year PAST }\end{array}$ & 77019,91 & 36510,05 & 40509,86 & 44929,95 \\
$\begin{array}{l}\text { Um ano CNR } \\
\text { One year CNR }\end{array}$ & 81196,83 & 41151,17 & 40045,65 & 42801,92 \\
$\begin{array}{l}\text { Um ano SIL } \\
\text { One year SIL }\end{array}$ & 81196,83 & 40195,50 & 41001,32 & 43757,59 \\
$\begin{array}{l}\text { Dois anos } \\
\text { Two years } \\
\text { Tradicional } \\
\text { Traditional }\end{array}$ & 73859,71 & 29792,72 & 44066,99 & 46556,78 \\
\hline
\end{tabular}

$\mathrm{R} \$ 1,00=\mathrm{U} \$ 0,87$.

sobre os sistemas "um ano" analisados tem duas respostas: o preço dos insumos no ano agrícola (19951996) analisado (RUIZ, 1990) e a baixa lotação que o campo nativo suporta no período de outono (JACQUES, 1993). Segundo ROCHA (1997), o maior ou menor potencial do sistema "um ano" para elevar a rentabilidade de um rebanho depende, certamente, do custo da alimentação hibernal adicional para manter a taxa adequada de crescimento das novilhas, a qual poderá exceder qualquer acréscimo na renda da produção subsequente de bezerros.

SHORT et al. (1994) ressaltam a necessidade de continuar a realização de sistemas "dois anos", em função de existirem condições ambientais, raças ou mestiços de puberdade mais tardia, sistemas de manejo sem condições de intensificação e, especialmente, limitações em quantidade ou qualidade de forragem em determinada época do ano. O Brasil com regiões tão distintas tem os quatro fatores nas suas regiões de pecuária. No Brasil Central, concentramse duas: o predomínio de uma raça mais tardia, Nelore, em que LOBATO $(1984 ; 1997)$ destaca a sua adaptação ao meio e a necessidade de sua manutenção em sistemas de cruzamentos em qualquer região, e os sistemas de manejo menos intensivos, principalmente pelas grandes extensões existentes.

No Rio Grande do Sul, os meses de outono, início do inverno, limitam a condução do sistema "um ano" sobre pastagens naturais ou melhoradas perenes pela carência em qualidade e quantidade de forragem. LOBATO (1997) apontou algumas alternativas para superar este problema, considerando a necessidade de um manejo mais intensivo e a utilização de raças mais precoces: confecção de feno de boa qualidade (azevém, cornichão, trevos) nos meses de maior oferta e sobra forrageira; utilização de silagem na época de maior carência; utilização de pastagens com cornichão e trevo vermelho, previamente diferidos, para utilização outonal; e suplementação com ração. A escolha das alternativas é determinada pela relação entre preço produto/preço insumos, determinando sua eficiência econômica (RUIZ, 1990).

A margem bruta resultante da análise dos três sistemas "um ano" considerou a receita bruta em kg de peso vivo comercializados. Outros sistemas que agreguem mais valor ao produto, como a venda de reprodutores, podem apresentar resultado diferenciado (LOBATO, 1997).

O sistema "um ano" também apresenta maior função social. Segundo LOBATO (1994), os produtores que realizam sistema "um ano" usam tecnologia, necessitam de mão-de-obra mais qualificada e, assim, são introdutores de melhor nível social no campo, tendo os empreendimentos rurais como fatores geradores e distribuidores de renda, com crescimento vertical, não considerando o empreendimento como depósito de capital.

SHORT et al. (1994) citaram como vantagens do sistema "um ano" o retorno mais rápido do investimento, mais bezerros por vida útil da vaca e aumento da receita bruta. Como desvantagem mais evidente, citou-se o aumento dos insumos.

LOBATO (1995) enfatizou que a agropecuária atual e futura só aumentará sua produtividade com o 
uso racional da tecnologia existente, gerada pelos órgãos de pesquisa, universidades nacionais e estrangeiras. MIELITZ NETTO (1994) constatou que é necessário um plano que priorize e incremente a etapa de criação, na qual se encontram as maiores restrições do ponto de vista técnico a possível crescimento. Inevitável desvantagem da espécie bovina em relação a outras - o período de gestação - deve ser superada pelo uso conjugado dos conhecimentos técnicos existentes, suficientes para incremento significativo da produtividade (LOBATO, 1997).

\section{Conclusões}

Foi observado custo variável mais elevado no sistema "um ano" CNR.

O sistema que apresentou a maior margem bruta é o "dois anos".

Sistemas que fazem uso de uma tecnologia mais intensiva sempre apresentam melhores resultados, quando comparados ao sistema "tradicional" de produção de bovinos de corte.

Os sistemas mais intensivos oferecem grande espectro de alternativas técnicas e econômicas a serem exploradas.

\section{Referências Bibliográficas}

FREITAS, E.A.G., LÓPEZ, J., PRATES, E.R. 1976. Produtividade, matéria seca, proteína digestível e nutrientes digestíveis totais em pastagem nativa do Rio Grande do Sul. Anuário Técnico IPZFO, 3(1):454-515.

GRAWUNDER, A.F. 1992. Custos e rentabilidade da pecuária no sul do Brasil. 32p. Estudio sobre Competitividad de Productos Agropecuarios en el MERCOSUR. Porto Alegre: IEPE.

GRAWUNDER, A.F. 1994. Modelo para gado de corte: Rio Grande do Sul. Porto Alegre: IEPE. 5p. Mimeo.

GRAWUNDER, A.F. 1988. Pecuária de corte: um avanço tecnológico apreciável. Lav. Arroz., 41(378):18-26.

JACQUES, A.V.A. Melhoramento de pastagens naturais: introdução de espécies de estação fria. In: CAMPO NATIVO. MELHORAMENTO E MANEJO, 1993, Esteio. Anais ... Esteio: FEDERACITE, 1993. p.24-31.

LOBATO, J.F.P. 1984. Bovinos de corte: seleção e sistemas de acasalamento. Porto Alegre: Adubos Trevo. 20p.

LOBATO, J.F.P. 1985. Gado de cria: tópicos. Porto Alegre: Adubos Trevo. 32p.

LOBATO, J.F.P. Manejo nutricional dos bovinos. In: SIMPÓSIO IVOMEC: A PECUÁRIA BRASILEIRA RUMO AO SÉCULO XXI, 1995, São Paulo. São Paulo: MSD AGVET, 1995. p.18-35.

LOBATO, J.F.P. 1994. Renovação na pecuária e agricultura. Jornal Ponche Verde, Dom Pedrito. 06 de ago. p.2.

LOBATO, J.F.P. Sistemas intensivos de produção de carne bovina: 1.cria. In: SIMPÓSIO SOBRE PECUÁRIA DE CORTE, 4, 1996, Piracicaba. Anais... Piracicaba: FEALQESALQ, 1997. p.161-204.
MIELITZ NETTO, C.G.A. Análise das mudanças de alguns coeficientes técnicos na criação de bovinos de corte no RS. Porto Alegre, 1979. 62p. Dissertação (Mestrado em Economia Rural) - Universidade Federal do Rio Grande do Sul, 1979.

MIELITZ NETTO, C.G.A. Modernização e diferenciação na bovinocultura de corte brasileira. Campinas, 1994. 224p. Tese (Doutorado em Economia) - Instituto de Economia, Universidade Estadual de Campinas, 1994.

PÖTTER, L. 1995. Custo de diferentes manejos alimentares para recria e terminação de terneiros de corte. In: SEMINÁRIOS APRESENTADOS NO CURSO DE PÓS-GRADUAÇÃO EM AGRONOMIA: ÁREA DE ZOOTECNIA, 1994/1995. Porto Alegre: Faculdade de Agronomia, Universidade Federal do Rio Grande do Sul.

PÖTTER, L. 1996. Preço de insumos no ano agrícola 1995/1996. Dom Pedrito: s.n., 35p. Relatórios internos da Empresa.

PÖTTER, V.J., SILVA, L.F.A. 1986. Perspectivas econômicas das pastagens melhoradas. Dom Pedrito: s.n. 11p.

ROCHA, M.G. da. Desenvolvimento e características de produção e reprodução de fêmeas de corte primíparas aos dois anos de idade. Porto Alegre, 1997. 244p. Tese (Doutorado em Zootecnia) - Universidade Federal do Rio Grande do Sul, 1997.

RUIZ, M.E. 1990. Metodologia para ensayos de produccion: crecimiento y engorde. In: RUIZ, E., RUIZ, A. (Eds.) Nutrición de ruminantes: guia metodológica de investigación. San José: IICA-RISPAL. p.269-288.

SAFRAS \& CIFRAS. 1996. Indicadores econômicos: bovinos de corte. Pelotas: Safras \& Sifras. 14p.

SHORT, R.E., STAIGMILLER, R.B., BELLOWS, R.A. et al. 1994. Breeding heifers at one year of age: biological and economic considerations. In: FIELDS, M.J., SAND, R.S. (Eds.) Factors affecting calf crop. Gainesville: CRC Press. p.55-68.

Recebido em: 20/10/98

Aceito em: 25/10/99 